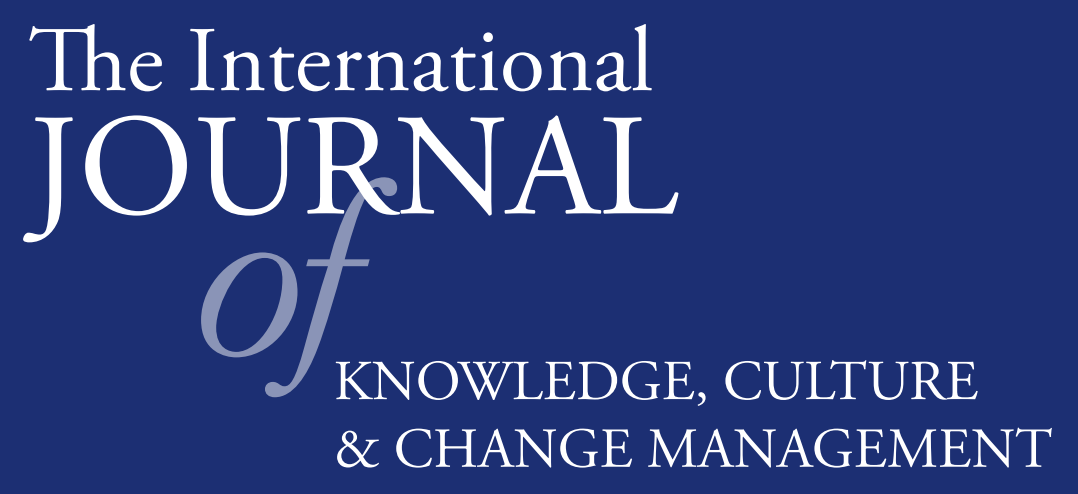

Volume 7, Number 8

Continuing Professional Development in Higher Education: Debating the Academic Perspective

Karin Crawford 
THE INTERNATIONAL JOURNAL OF KNOWLEDGE, CULTURE AND CHANGE MANAGEMENT http://www.Management-Journal.com

First published in 2007 in Melbourne, Australia by Common Ground Publishing Pty Ltd www.CommonGroundPublishing.com.

(C) 2007 (individual papers), the author(s)

(C) 2007 (selection and editorial matter) Common Ground

Authors are responsible for the accuracy of citations, quotations, diagrams, tables and maps.

All rights reserved. Apart from fair use for the purposes of study, research, criticism or review as permitted under the Copyright Act (Australia), no part of this work may be reproduced without written permission from the publisher. For permissions and other inquiries, please contact <cg-support@commongroundpublishing.com>.

ISSN: $1447-9524$

Publisher Site: http://www.Management-Journal.com

THE INTERNATIONAL JOURNAL OF KNOWLEDGE, CULTURE AND CHANGE MANAGEMENT is a peer refereed journal. Full papers submitted for publication are refereed by Associate Editors through anonymous referee processes.

Typeset in Common Ground Markup Language using CGCreator multichannel typesetting system http://www.CommonGroundSoftware.com. 


\title{
Continuing Professional Development in Higher Education: Debating the Academic Perspective
}

\author{
Karin Crawford, University of Lincoln, UK
}

\begin{abstract}
This paper provides an overview of a research project in progress and the debates it addresses. The three-year project is set within the context of contemporary UK Higher Education (HE) policy. The paper summarises the research which focuses on developing an understanding of the influences on Continuing Professional Development (CPD) practices in academia, in particular exploring how academics interpret their responsibilities for their own lifelong learning and knowledge creation within the learning organisation. This paper provides an overview of the research context, before exploring relevant current debates and issues from the literature. In this way, the author raises some of the contemporary debates and dilemmas in relation to CPD in Higher Education; examples include: the intention and influence of national policy, including analysis of how higher education policy is interpreted, implemented and impacts upon practice; how CPD is defined and understood; collectivity and social learning in academia; and the motivations, intentions and actions of academics in respect of CPD. In the light of the discussion, the research project's overall purpose, aims, rationale and key questions are detailed. The conceptual and theoretical framework that underpins this work is taken from 'third generation activity theory', its principles and assumptions are also elaborated within this paper. The paper therefore raises debates and apparent tensions and dilemmas related to CPD in academia. In view of those debates, the qualitative multi-case study project outlined in the paper, which has a distinct and original focus on the perspective and 'voices' of academics, is likely to result in outcomes that are important and significant for a range of stakeholders across the higher education sector.
\end{abstract}

Keywords: Continuing Professional Development, Higher Education, Academics, Lifelong Learning

\section{Introduction}

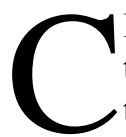

LEGG (2003: 37) raises the concern that the CPD 'of professionals in higher education .... operates around a series of unresolved tensions'. It is this concern about CPD practices in academia, with a focus on how academics interpret their responsibilities for their own lifelong learning and knowledge creation within Universities as learning organisations, which forms the focus of this paper and the research work that it discusses. The research is investigating and analysing influences on the CPD behaviours of academics in $\mathrm{HE}$ in the United Kingdom (UK). This paper provides an overview of the research context, before exploring relevant current debates and issues from the literature. In the light of the discussion, the research project's overall purpose, aims, rationale and key questions are detailed. The conceptual and theoretical framework that underpins this work is taken from 'third generation activity theory', its principles and assumptions are also elaborated within this paper.

It is important to note, at the outset, that whilst this paper is underpinned by the author's view that $\mathrm{CPD}$, in its broadest sense, is relevant, necessary and worthwhile for academics to engage in, CPD is 'neither innocent nor neutral' (McWilliam 2002: 289). It is not possible, in the space available here, to explore the debate further, however knowledge that it exists, that it is relevant to the research purposes and will form part of the overall investigation, is pertinent.

\section{The Context of Contemporary Higher Education in the United Kingdom}

CPD in UK Higher Education can be seen to take place in a fluid and changing environment. For this reason, a significant aspect of the research is to explore further the national and institutional context of CPD and whether this influences the perspectives, behaviours and attitudes of academics working in that environment. According to the Higher Education Funding Council (HEFCE 2005: 2), 'Higher education in the UK is rich and diverse. It is provided by many types of institutions, which carry out teaching, scholarship and research'. All of these institutions, usually colleges and universities, are independent and self-governing, but vary greatly, for example, in their historical backgrounds, size, location, and the forms of learning and subjects offered. There is a further perceived difference between original universities, established before 1992 by Royal Charter or Act of Parliament, and those universities which were formerly polytechnics or colleges and were given the status of universities under the Further and Higher Education Act 1992. This 'binary line'

THE INTERNATIONAL JOURNAL OF KNOWLEDGE, CULTURE AND CHANGE MANAGEMENT, VOLUME 7, NUMBER 8, 2007

http://www.Management-Journal.com, ISSN 1447-9524

c Common Ground, Karin Crawford, All Rights Reserved, Permissions: cg-support@commongroundpublishing.com 
between the historically different institutions remains applicable to understanding some of the apparent variations (Deem 1998: 48).

Later in the same decade, some ten years ago, the government commissioned a study of HE to report with 'recommendations on how the purposes, shape, structure, size and funding of higher education . . . should develop . . . over the next 20 years' (NCIHE 1997: 3). This report, known by the name of its chairman, The Dearing Report, continues to be influential today. However, its recommendations have been criticised for proposing 'a series of uneasy compromises between market forces, state control and professional interests' (Tapper and Salter 1998: $33)$ in the HE sector. Deem (1998: 53) takes this further in discussing the 'hybridisation of managerial processes' in universities which have arisen in response to financial constraints and 'critiques of professional power' (ibid: 50). Further evidence of the new managerialist discourse in the context of HE can be found in the more recent government white paper 'The Future of HE' (DfES 2003) wherein, amongst a rhetoric of more freedom and self-determination for universities, examples of a furthering of the new managerialist discourse of 'recognition and reward' (Ibid: 51); 'quality and standards systems' (Ibid: 50); competition; and economic efficiency, are apparent.

Furthermore, and illustrative of these approaches, there has been an increasing focus on '...goodquality teaching for everyone...' (DfES 2003: 49) by '...staff that are trained to teach and continue to develop professionally...' (ibid). Accordingly, the Higher Education Academy, which was created following the publication of the White Paper, developed the 'UK Professional Standards Framework for teaching and supporting learning in higher education' (HEA, 2006). These standards aim to act as 'an enabling mechanism to support the professional development of staff engaged in supporting learning' and 'a means of demonstrating to students and other stakeholders the professionalism that staff bring to the support of the student learning experience' (www.heacademy.ac.uk). The underpinning areas of activity within the standards framework include the 'evaluation of practice and continuing professional development' (CPD) and the professional value of a 'commitment to continuing professional development and evaluation of practice' (ibid). The Higher Education Academy is now in the process of piloting and developing an accreditation process for CPD frameworks within institutions.

The quality of teaching has become a significant consideration of the audit processes of the Quality Assurance Agency (QAA) (www.qaa.ac.uk). As such, HEIs have become overtly accountable for the 'teaching quality information' emerging from such audits which is then publicly available. Additionally, the Higher Education Funding Council for England (HEFCE) provides a strategic lead to 'support institutions in enhancing the quality of their learning and teaching' (www.hefce.ac.uk). The development of learning and teaching strategies and their implementation within institutions is also supported through HEFCE funding under the Teaching Quality Enhancement Fund. To attract financial support through this funding Higher Education Institutions are required to set out three year action-plans, identify priority areas for investment and commit to annual monitoring and reporting agreements (www.hefce.ac.uk).

\section{Theoretical and Conceptual Framework}

It can be seen therefore, that the research environment and context is complex and fluid. 'To be able to analyze such complex interactions and relationships, a theoretical account of the constitutive elements of the system under investigation is needed' (Engeström and Miettinen 1999: 9). Nash (2002: 398) argues that it is necessary to use an approach which is capable of giving 'an account of mechanism and process . . . in terms of system properties, individual dispositions and individual action within recognised social practice, in such a way that the effective linkages between these levels may be demonstrated'. Thus, in order, not only to foreground the theoretical and ideological assumptions that are embedded in the research aims and objectives, but also to give coherence throughout the research design and process, the project is informed by the concepts of 'third generation' activity theory (Engeström 2001, Daniels 2004).

It is through the activity theory framework that exploration of linkages will be made, enabling analysis of relationships and construction of 'an explanatory narrative of the social process(es)' within academic communities (ibid: 398). In other words, the research will endeavour to uncover the practical, the personal and political facets of the concerns. Activity theory is considered a useful, systematic tool to assist evaluation of the 'relationship between the micro and macro levels of analysis' (Engeström and Miettinen 1999: 8). The theory is underpinned by a perspective that individual action and behaviours are influenced by factors in the environment (ZuberSkerritt 1992, Engeström and Miettinen 1999, Daniels 2004), which is a significant aspect of consideration for the debates and the research outlined in this paper, which aims to consider the structural, national policy context; the organisational context; and influences stemming from individual difference.

Whilst allowing for 'a common conceptual and methodological core' (Engeström and Miettinen 1999: 2), activity theory can be seen to encompass 
perspectives from a number of other approaches. For example, Wenger (1998) develops an approach to Social Learning Theory which conceptualises learning as acquired through engagement, social interaction and community. Similarly, activity theory, whilst it enables an understanding of the behaviours of individuals, starts from the perspective of joint activity, practice and the process of social transformation as the unit of analysis (Engeström 1999). The approach also builds the work of Vygotsky (1978) (Zone of Proximal Development) into the concept of 'expansive learning' which underpins enhanced professional practice (Daniels 2004).

Activity theory conceptualises the relationship between a range of interdependent elements operating with an activity system. There are six factors which are seen to mediate the activity (Engeström 1999); the overall 'object' of the collective activity system; the 'subject', person or group of individuals who are engaged in the activity; the 'community' or social relations in the system; the 'division of labour' which directs the balance of roles and responsibilities; the 'tools and artefacts' which form the resources and means to support the activity; and the 'rules' which are supported, accepted or imposed within the activity system. Activity theory is therefore descriptive rather than prescriptive, in that it does not suggest a solution, but describes processes. As a theoretical framework for this research, activity theory facilitates investigation of consistencies, contradictions and tensions where these interrelated elements are connected in the activity system that is HE.

\section{Contemporary Debates and Challenges}

It is worthy of note that there is a dearth of empirical evidence that emanates from the perspective of academics, and that therefore, this research has necessarily adopted a wider perspective when exploring the debates and earlier work in this area. In her theoretical meta-analysis of CPD in HE, Clegg argues that 'the problem of CPD ... of professionals in higher education is that it operates around a series of unresolved tensions' (2003: 37). The 'fault lines in conceptualising' (ibid) CPD can be seen as arising from three interconnected areas of debate; issues related to the appropriate content and focus of CPD; differences in the form and approach to what constitutes CPD activity; the relationship between policy, implementation, institutional and individual interests. Each of these tensions will now be considered.

Clegg (2003: 38) argues that there are two 'dualisms' in respect of what is considered appropriate content and focus of CPD in HE, and that these dualism's reflect characteristic influences on academic identity. The two opposing concepts are the researchteaching nexus and orientations or loyalties to discip- line-organisation. Both of these areas of tension can be seen to have potential impact across the activity system particularly the interface between the subject, the academic; the 'rules'; 'community' and 'division of effort and labour'.

\section{The Academic Role}

With respect to the first of these, there has been much written about the links between teaching and research, and the relative status and importance afforded to each area of activity within HEIs (Barnett 2005). The perceived 'disproportionate status and reward accorded to research in universities' (Trigwell and Shale 2004: 523) with the emergence of 'two academic tribes - those who prioritize research within their career, and those who tend to prioritize teaching' (Ramsden, cited in Trigwell and Shale 2004: 523) has consequent implications for CPD, its development, interpretation and impetus in the institution (Clegg 2003). Potentially relationships within the activity system are further complicated by the requirement for organisations to implement the UK Professional Standards Framework for teaching and supporting learning in HE (HEA 2006). Traditionally academics were seen to engage in teaching, research and administration, however, the reality is that the 'academic role is in flux' and can include a wider range of tasks and responsibilities (Blackmore and Blackwell 2003: 19). The Professional Standards Framework, which focuses on teaching and learning, may not therefore enable academics and institutions to take a more inclusive approach to considering CPD.

Similarly, as Clegg (2003) suggests, there are significant disciplinary differences in approaches to CPD. Allan et al (2003) see these differences as evolving from epistemological sources and liken the outcome to 'tribes and territories' (ibid: 66). Academics are positioned within many systems or communities, each of which may have different discourses; understandings of CPD; approaches to teaching and learning; and priorities. The conception of discourse and a 'shared repertoire' within disciplines, is considered significant to professional identity and 'community' membership (Wenger 1998:82). The wider notion of communication is a fundamental aspect of 'object-orientated practical activity' (Engeström and Miettinen 1999: 7), so much so, that language and the understandings attributed to it become part of the armoury of the 'tools and artefacts' of academia. Further to this there is a view that some academic staff may only give credence to development opportunities created and offered from within their own disciplinary area (Jenkins cited in Allan et al 2003). Also of relevance are the potentially competing approaches and needs of the discipline 
and the institution. It is considered that academics most frequently prioritise development in their disciplinary area, where they may have the most interest and confidence, above developing their skills and knowledge in teaching (Allan et al 2003, ZuberSkerritt 1992). 'These disciplinary orientations and their organisational forms are important when it comes to understanding individual and institutional responses to formal academic or staff development.' (Clegg 2003: 39)

\section{Defining Continuing Professional Development Activity}

In addition to inconsistencies related to the content and focus of CPD there is clear variance about the appropriate form and approach to CPD activity. The core of the issue can be seen to pivot on whether CPD activity is inclusive of formal and informal approaches to learning in the workplace or not. There is 'a tendency to regard professional or staff development as comprising only those sorts of activities that are formally recognised' (Clegg 2003: 37) whilst 'not all professional knowings are explicit' (Knight 2006: 31). Taking the metaphor of an ice-berg, Knight (2006), who incidentally uses the phrase 'Educational Professional Development', argues that there is more tacit, contextual, situated knowledge below the surface, than there is formal, tangible and explicit knowledge above it. Following research into the CPD activities of a range of professionals, Becher (1999) highlights the significance of skills and knowledge being developed through normal working activities. Clegg (2003) similarly suggests that 'some of the most significant activities academics engage in through personal scholarship are not usually conceptualised as CPD'. Billett (2002: 58) argues that the dichotomous distinction between 'formal' and 'informal' workplace learning is not helpful, suggesting that workplace learning needs to be framed as 'engagement in goal-directed activities that are structured by workplace experiences'.

Arguably though, 'ever increasing external demands placed upon institutions and individuals' (Cullingford 2002: 223) through for example, the impetus to meet the 'Professional Standards Framework for teaching and supporting learning in higher education' (HEA 2006) and institutional audit requirements, will further value professional development that is synonymous with formal approaches, such as accredited courses and training events. This potentially managerialist, output-led, audit culture is arguably being embedded in the 'rules', culture and policies of the institution as the activity system.

There is concern that the requirements and regulations can result in CPD being 'accountancy-driven' and as such development that cannot be scrutinised, evidenced and counted, will not be valued (Schuller and Field 2002:78). McWilliam (2002) adds to the voices of concern in raising disquiet about the standardisation and generalisation of professional development in a context (academia) that is valued for its ability to question and challenge. Field (2002: 211), discussing issues of 'measurability', identifies the complexity and suggests that there are only two opposing potential solutions; high levels of trust or strong regulation. Similarly Cullingford (2002: 223) argues that mistrust is an insidious theme of current accountability agendas. Essentially, these concerns can be seen to relate to the interdependencies within the activity system and particularly the interplay between academics and their environment. Engeström and Miettinen (1999: 9) suggest that 'internal tensions and contradictions of such a system are the motive force of change and development' and thus the 'continuous transitions and transformations' (ibid) that accompany the debates can be seen as the conduit for expansive learning in the system. Realistically, this may be a debate that has still to be surfaced in Higher Education, as for example the National Standards Framework and registered practitioner (with the HE Academy) status are currently unregulated. However, with current moves towards the development of national accreditation of CPD frameworks within institutions, levels of trust may be reducing.

The third area of potential difficulty, when deconstructing the meanings and understandings attributed to $\mathrm{CPD}$, centres on the relationship between policy, implementation, institutional and individual interests. In a critique of broader lifelong learning policies, Field (2002: 201) conveys concern about the effectiveness and implementation of policy, outlining the disparity between 'policy rhetoric and policy achievement' and 'conception and delivery'. In respect of CPD in academia, this may be partially explained by the apparent lack of consensus of the meaning and scope of the concept.

The HE Academy offers a definition of CPD which is developed from the Institute of Personnel and Development, 'CPD is systematic, on-going, self-directed learning. It is an approach or process which should be a normal part of how you plan and manage your whole working life' (HEA www.heacademcy.ac.uk/197.htm). In essence this definition may seem incontestable; however, this can be attributed to the broad approach taken, its ambiguity and lack of precision. It does not, for example, address the debates that are evident in the literature. This definition appears to focus on the individual yet Clegg (2003: 42) notes that the context for CPD in $\mathrm{HE}$ is largely created as a result of 'top-down institutional and quality agendas'. Thus 'the core tension in this relationship is that between those needs for 
the continuity of the work practice and individuals' needs to realise their personal or vocational goals' (Billett 2002: 56). From the perspective of activity theory, (Engeström and Miettinen 1999: 3), it is not possible to isolate progress and change as being instigated either from the institutional or individual level, as they are 'two mutually dependent aspects' that influence the activity. Similarly, but specifically referring to CPD in HE, Zuber-Skerritt suggests that this relationship is situated in mutually influential social processes, in that 'to change people means to create a different climate for generating different working relationships. Changed people are the result of changed climates, and changed climates are the results of changed people.' (Zuber-Skerritt 1992: 158).

\section{Competing Interests in Continuing Professional Development}

Thus, the literature evidences a range of views when exploring the institutional context of CPD and whose goals and needs should be the focus of relevant institutional strategies. Citing the work of Land (2001), Clegg (2003: 38) develops a distinction between 'domesticating tendencies' and 'critique', where the former aims to align CPD to the needs of the institution, and the latter has a more 'emancipatory purpose'. Whilst overtly favouring 'critique' and creative dialogue and indicating concern about processes of CDP being 'enmeshed with the reform quality agenda' (ibid: 45), Clegg concedes that institutional agendas can be more inclusive and less discriminatory, than forms of professional development that centre around exclusive networking.

Blackwell and Blackmore (2003) take this further and directly argue that the emphasis of any CPD strategy should be on more institutional and departmental alignment and away from a focus on individual academics. However, despite some acknowledgment of the strengths of institutionally-led approaches (see Clegg 2003, cited above), there is clear evidence through the literature of alternative approaches being advocated. For example, Knight (2006) suggests that whilst professional development is a strategic activity, it is located in 'distributed activity systems' which ensure alignment to context within collaborative working environments. Similarly Zuber-Skerritt (1992) warns that institutional bureaucracy jeopardises the development of knowledge through social communicative processes; the quality of workplace environments being seen as the central means of creating 'cultures of concern' and enhancing the quality of teaching and learning (Knight 2006: 36). Clegg cites the work of Knight and Trowler (2001 cited in Clegg 2003: 47) as she develops the concept of 'making the academic department the hub of activities'. However, Clegg (2003) continues to stress the importance of central functions in the institution, so arguably develops a stance akin to Blackwell and Blackmore who echo the views expressed by Engeström and Miettinen (1999) and Zuber-Skerritt (1992) in suggesting that 'the analytical distinction between individually focused and organisationally focused development is in practice blurred and the relative 'gain' from learning is often shared in somewhat unpredictable proportions. (2003: 14).

\section{Outlining the Research Project}

Thus, the author's reading of the literature indicates that there are a range of tensions and complexities that result in the notion of CPD being fluid, subjective and potentially attributed with a number of contestable meanings. Using the term 'staff development', Blackwell and Blackmore (2003: 3) concur and suggest that not only is there 'no settled meaning', but that there is unlikely ever to be one. Arguably, though, we should not be concerned by the lack of consensus about what CPD means, but realise that by recognising the tensions and 'problematising' the concept, we acknowledge the complexities and encourage participative debate (Clegg 2003) and potentially have 'the motive force of change and development' (Engeström and Miettinen 1999: 9).

In view of the tensions that are raised through the literature, the lack of data on the views of academics themselves, and the changing contemporary context of HE, the current research project becomes highly pertinent and significant. The research aims to offer insight into the views and perspectives of academics with the intention that this knowledge will be helpful in shaping the way in which HEIs enable effective professional development across academic staff. Therefore, this project will be conducted within an interpretive framework, using qualitative research methodology. As such, the underpinning philosophical perspective is one that focuses on the subjective experience and meanings constructed by individuals (Morrison 2002:19, Cohen et al 2000:22). In addressing the research questions, qualitative research practices may incorporate a number of methodological approaches (Denzin and Lincoln 1994: 3). For this project, semi-structured interviews, interviews with key informants and documentary data analysis will be employed within a multi-case study approach. Sample 'cases' will be taken from a small number of HE institutions representing the historical differences outlined earlier in the paper. The author suggests that this 'multiple-case sampling adds confidence to findings' (Miles and Hubermann 1994: 29, italics in original) allowing for the highest possibility of transferability of findings. However, Yin (cited 
in Miles and Hubermann 1994: 26) emphasises that some 'cases' may themselves have many 'sub-cases embedded in them'. Indeed within Universities, there are faculties, departments, disciplines or subjects, teams and even specific teaching or research teams which may be seen as 'sub-cases'.

The research is both timely and pertinent given the current context of HE as outlined earlier. Thus, for example, academics are working with changing national policy directives; increasing and shifting demands and expectations being made both on their employing institutions and on themselves as professionals (Cullingford 2002); and, potentially in response to some of these drivers, change in organisational structures which impact upon their work. These changes, though, are arguably mitigated by continuity, for example, as maintained by Knight (2002), the spread of quality assurance practices may influence, but does not determine, professional identity. The influences of these changes and continuities on how academics perceive and respond to CPD form the focus of the research project.

\section{Conclusion}

It has been argued that 'top down institutional and quality agendas shape the context for much CPD'
(Clegg 2003: 42). In contrast, the author contends that to develop a meaningful understanding of CPD practices in academia, it is necessary to start with an exploration of what academics understand by CPD, what they do and why, taking account of the context within which that happens. Furthermore, as an academic working in HE, the author defends this research for its reflective and reflexive nature. In this way, the author and individual participants become the nucleus and focal point of the research. As Dill (2005: 178) states 'it is equally (...) important for the continuance of the university as we know it that we look systematically and critically at our own professional behaviour, at our structures of university self-governance, at our processes for peer review and at our underlying academic beliefs'

In conclusion, this paper has debated apparent tensions and dilemmas related to CPD in academia. In the light of the literature, a current research project that is investigating and analysing influences on the CPD behaviours of academics in HE through the theoretical framework of activity theory, has been outlined. This qualitative multi-case study project, with its distinct and original focus on the perspective and 'voices' of academics, is likely to result in outcomes that are important and significant for a range of stakeholders across the higher education sector.

\section{References}

Allan, C., Blackwell, R. and Gibbs, G. (2003) 'Developing the subject dimension to staff development' in R. Blackwell and P. Blackmore (Eds)Towards Strategic Staff Development in Higher Education' Pp66-78

Barnett, R. (Ed) (2005) Reshaping the University: New Relationships between Research, Scholarship and Teaching Berkshire: Open University Press

Becher, T. (1999) Professional Practices: Commitment and capability in a changing environment New Jersey: Transaction Publishers

Billett, S. R. (2002) ‘Critiquing workplace learning discourses: Participation and continuity at work' Studies in the Education of Adults 34 (1) Pp56-67

Blackmore, P. and Blackwell, R. (2003) 'Academic roles and relationships' in R. Blackwell and P. Blackmore (Eds) Towards Strategic Staff Development in Higher Education' Pp16-28

Blackwell, R. and Blackmore, P. (2003) 'Rethinking strategic staff development' in R. Blackwell and P. Blackmore (Eds)Towards Strategic Staff Development in Higher Education' Pp3-15

Clegg, S. (2003) 'Problematising Ourselves: Continuing Professional Development in Higher Education' International Journal for Academic Development Vol 8 (1/2) Pp.37-50

Cohen, L., Manion, L and Morrison, K (2000) Research Methods in Education $\left(5^{\text {th }}\right.$ Ed) London: RoutledgeFalmer

Cullingford, C. (2002) 'Institutional Development and Professional Needs: Some Reflections' in G. Trorey and C. Cullingford (Eds) Professional Development and Institutional Needs Aldershot: Ashgate Publishing

Daniels, H. (2004) 'Cultural Historical Activity theory and Professional Learning' International Journal of Disability, Development and Education Vol 51 (2) Pp 185-200

Dearing, R (1997) Report of the National Committee of Enquiry into Higher Education London: HMSO

Deem, R. (1998) 'New Managerialism' and Higher Education: the management of performances and cultures in universities in the United Kingdom' International Studies in Sociology of Education Vol 8 (1) p.47-70

Denzin, N. K. and Lincoln, Y. S. (1994) 'Introduction: The Discipline and Practice of Qualitative Research' in N. K. Denzin and Y. S. Lincoln (1994) (eds) Handbook of Qualitative Research London: Sage publications

Denzin, N. K and Lincoln, Y. S. (Eds) (1998) Collecting and Interpreting Qualitative Materials London: Sage publications Department for Education and Skills (DfES) (2003) The future of higher education The Stationery Office

Dill, D. D. (2005) 'The Degradation of the Academic Ethic: Teaching, Research and the Renewal of Professional SelfRegulation' in R. Barnett (Ed) Reshaping the University Pp.178-191 Berkshire: Open University Press

Engeström, Y. and Miettinen (1999) 'Introduction' in Y. Engeström., R. Miettinen and R-L. Punamäki (1999) (Eds) Perspectives on Activity theory Cambridge: Cambridge University Press 
Engeström, Y. (1999) 'Activity theory and individual and social transformation' in Y. Engeström., R. Miettinen and R-L. Punamäki (1999) (Eds) Perspectives on Activity theory Cambridge: Cambridge University Press

Engeström, Y. (2001) 'Expansive Learning at Work: toward an activity theoretical reconceptualization' in Journal of Education and Work Vol 14 (1) Pp 133-156

Field, J (2002) 'Governing the ungovernable: why lifelong learning policies promise so much yet deliver so little' in R. Edwards, N. Miller, N. Small and A. Tait (Eds) Supporting Lifelong Learning Volume 3, Making Policy Work. London: Routledge

Higher Education Academy (HEA) (2006) The UK Professional Sta $n$ dards Framework for teaching and supporting learning in higher educ a tion www.heacademy.ac.uk

Higher Education Funding Council (HEFCE) (2005) Guide: Higher Education in the United Kingdom Bristol: HEFCE www.hefce.ac.uk/pubs

Knight, P. T. (2002) Being a Teaching in Higher Education Buckingham: SRHE and Open University Press.

Knight, P. (2006) 'Quality Enhancement and Educational Professional Development' Quality in Higher Education Vol 12 (1) Pp.29-40

McWilliam, E. (2002) 'Against Professional Development' in Educational Philosophy and Theory Vol. 34 (3) Pp 289-299

Miles, M. B. and Hubermann, A. M (1994) Qualitative Data Analysis ( ${ }^{\text {nd }}$ Ed) London: Sage publications

Morrison, M (2002) What do we mean by educational research? In Coleman, M and Briggs, A (Eds) (2002) Research Methods in Educational Leadership and Management London: Paul Chapman

Nash, R (2002) Numbers and Narratives: further reflections in the soc i ology of education British Journal of Sociology of Education Vol. 23 (3) Pp 397-412

National Committee of Inquiry into Higher Education (NCIHE) (1997) Higher Education in the Learning Society: summary report Norwich: HMSO

Schuller, T and Field J (2002) 'Social capital, human capital and the learning society' in R. Edwards, N. Miller, N. Small and A. Tait (Eds) Supporting Lifelong Learning Volume 3, Making Policy Work. London: Routledge

Tapper, E. P. and Salter, B. G. (1998) 'The Dearing Report and the Maintenance of Academic Standards: Towards a New Academic Corporatism' Higher Education Quarterly Vol 52 (1) Pp.22-34

Trigwell, K. and Shale, S. (2004) 'Student learning and the scholarship of university teaching' Studies in Higher Education Vol 29 (4). Pp524-525

Universities UK www.universitiesuk.ac.uk [accessed 03 June 2007]

Vygotsky, L. S. (1978) Mind and Society: The development of higher mental processes Cambridge, MA: Harvard University Press

Wenger, E. (1998) Communities of Practice: Learning, Meaning, and Identity Cambridge: Cambridge University Press

Zuber-Skerritt, O. (1992) Professional Development in Higher Education London: Kogan Page

\section{About the Author}

Karin Crawford

Karin Crawford is a Principal Teaching Fellow at the University of Lincoln, School of Health and Social Care. Teaching on both undergraduate and postgraduate programmes, Karin is also involved in research that spans both Health and Social Care subject-related and pedagogic-related research. Karin's interest in CPD and lifelong learning arises not only from her own learning journey through professional practice into academia, but also from earlier research exploring attitudes towards CPD in Social Work following changes in national policy. 



\section{THE INTERNATIONAL JOURNAL OF KNOWLEDGE, CULTURE AND CHANGE MANAGEMENT}

\section{EDITORS}

Mary Kalantzis, University of Illinois, Urbana-Champaign, USA.

Bill Cope, University of Illinois, Urbana-Champaign, USA.

\section{EDITORIAL ADVISORY BOARD}

Verna Allee, Verna Allee Associates, California, USA.

Zainal Ariffin, Universiti Sains Malaysia, Penang, Malaysia.

Robert Brooks, Monash University, Melbourne, Australia.

Bruce Cronin, University of Greenwich, UK.

Rod Dilnutt, William Bethway and Associates, Melbourne, Australia.

Judith Ellis, Enterprise Knowledge, Melbourne, Australia.

Andrea Fried, Chemnitz University of Technology, Germany.

David Gurteen, Gurteen Knowledge, UK.

David Hakken, University of Indiana, Bloomington, Indiana, USA.

Sabine Hoffmann, Macquarie University, Australia.

Stavros Ioannides, Pantion University, Athens, Greece.

Margaret Jackson, RMIT University, Melbourne, Australia.

Paul James, RMIT University, Melbourne, Australia.

Leslie Johnson, University of Greenwich, UK.

Eleni Karantzola, University of the Aegean, Rhodes, Greece.

Gerasimos Kouzelis, University of Athens, Greece.

Krishan Kumar, University of Virginia, USA.

Martyn Laycock, University of Greenwich and managingtransitions.net, UK.

David Lyon, Queens University, Ontario, Canada.

Bill Martin, RMIT University, Melbourne, Australia.

Pumela Msweli-Mbanga, University of Kwazulu-Natal, South Africa.

Claudia Schmitz, Cenandu Learning Agency, Germany.

Kirpal Singh, Singapore Management University, Singapore.

Dave Snowden, Cynefin Centre for Organisational Complexity, UK.

Chryssi Vitsilakis-Soroniatis, University of the Aegean, Rhodes, Greece.

Please visit the Journal website at http://www.Management-Journal.com for further information:

- ABOUT the Journal including Scope and Concerns, Editors, Advisory Board, Associate Editors and Journal Profile

- FOR AUTHORS including Publishing Policy, Submission Guidelines, Peer Review Process and Publishing Agreement

\section{SUBSCRIPTIONS}

The Journal offers individual and institutional subscriptions. For further information please visit http://ijm.cgpublisher.com/subscriptions.html. Inquiries can be directed to subscriptions@.commongroundpublishing.com 